\title{
Open Data Institute/Institute of Direct and Digital Marketing joint event
}

This is for everyone

\section{Standards, support and training}

\section{Identifying patterns in big data}

\section{Telefónica Dynamic Insights}

Journal of Direct, Data and Digital Marketing Practice (2013) 15, 176-179. doi:10.1057/dddmp.2013.55

When Tim Berners-Lee opened the London Olympic Games 2012 with the tweet 'This is for everyone' broadcast around the stadium, it was a statement about how the world wide web is meant to be open and democratic. However, it could equally serve as a mission statement for the Open Data movement, not least since Berners-Lee is one of the co-founders of the Open Data Institute (ODI).

Stuart Coleman, commercial director of the ODI, used the same slogan to open the first ODI/Institute of Direct and Digital Marketing event, held on 22 October to launch the new joint training programme on Open Data for Marketers. 'The open web has become the most successful information-sharing system of all time. But there is a lot more information we could use and we're here to help people make sense of it', he said.

The institute is using three strategies to make this happen: standards for those working on open data, support for start-ups, and training and education. Speaking to a mixed audience drawn from both the open data world and the more conventional marketing data space, Coleman explained the critical difference between personal data, big data and open data. 'Open data is freely available for use and is not personal - that would break ICO guidelines', he said.

Already, 15,000 different public sector data sets have been opened up via http://www.data.gov.uk, but Coleman said the process needs to get easier. 'What can you do with it? We are looking to identify the potential through projects such as OpenHealthLab, which took anonymised data on prescriptions for every primary care trust and GP, then used Hadoop to mine it. That told us in some areas GPs are over-prescribing brand-name statins for cardio-vascular conditions, even though they cost twenty times the generic equivalent. NHS guidelines are to prescribe generics - if that happened it would save $£ 200 \mathrm{~m}$ a year', he said.

As an example of how open and big data cross over, that data source comprises 100 million rows every month. In a second example, Coleman explained how a peer-to-peer lending organization opened up data on its 14 million records covering $£ 378 \mathrm{~m}$ of loans. This identified that while the lending was distributed evenly to borrowers right across the United Kingdom, it was largely originating in the South East. 'That sort of insight could be used by the banking sector to identify patterns of lending ahead of new regulations in 2014', he said, especially with non-traditional lending having grown 80 per cent year-on-year during the downturn.

Telefónica UK became a partner of the ODI in July 2013 as part of its open data strategy. Hugo Pinto, sector communications manager of 


\section{Profiling customers versus non-customers}

ScraperWiki

Provenance
Telefónica Dynamic Insights, gave a presentation on some of the ways in which the network's data streams are being used in an anonymized form for entirely new purposes. He noted how careful the company is to ensure that it respects the privacy of its subscribers, given that ' 90 per cent of mobile users keep their phone within 1.5 metres at all times'.

This always-on activity generates data logs and call records, which provide a footprint of 1.1 billion events every day that can be analysed to understand user behaviour. This data is anonymized and aggregated to conceal individual identities and to ensure that they cannot be reverse engineered. 'There have been mis-givings about us knowing where people are at any time of day, but what we are actually doing is targeting people in crowds. So we can compare $6 \mathrm{pm}$ versus 2 am in Oxford Street, for example, or look at footfall at Christmas or when the street is only open to pedestrians. That has implications for retailers, the public sector, travel and more', said Pinto.

This data can be used in marketing planning, for example, to identify outdoor advertising spaces that will be seen by a target audience on their journey to work or when out shopping. Eventually, this level of profiling will be possible in real time. 'The data can be applied to a customer database at postcode level to identify customers versus non-customers and look at their behaviour, for example, who is in Chelsea on a match day compared to a non-match day. That changes the questions you can ask', he explained.

Emergency services may start to use O2's open data for planning their resources, combining anonymous profiles with GPS and mapping to look at where demand for ambulances is likely to be the highest, for example. The company is also working with the ODI and MIT to examine crime patterns and the possibility of predicting where events might occur.

Some of the predictions for the power of open (and big) data appear to have raised expectations to unrealistic levels. At one presentation this editor attended, for example, it was claimed that retailers in shopping malls were not interested in the data on phone users that is accurate to within 3 metres unless they could also tell which direction the person was walking in. Pinto noted that standard cell tracking operates to between 10-metre and 20-metre accuracy, although the technology does exist for closer encounters. 'It depends whether you want to spend $£ 100,000$ or $£ 1 \mathrm{~m}$ getting that data. What we can already do is improve on market research because our subscribers are 30 per cent of the population, so we can be very accurate', said Pinto.

He was followed onto the stage by a series of flash talks - 4-minute presentations by start-ups that the ODI is currently supporting. The first of these was by Francis Irving, CEO of ScraperWiki, a self-service platform that pulls open data from PDFs on websites and converts it into reports. One live application has been to pull insolvency records published by New Jersey, while another has been for a major social media platform that wanted to understand who among its users was a prospect for its paid-for tools by identifying followers of existing customers.

The second presentation came from Jessi Baker, co-founder of Provenance. 'Consumers increasingly want to know about the origin 


\section{CarbonCulture}

\section{IDM supporting employability for 15 years}

\section{Data now front-page news}

\section{Industry cannot rely on regulators to build trust}

of the products they buy, so we founded the business to help them', she explained. The web platform draws on open data to identify products and bring together information on how it has been sourced. Its initial focus is on fashion and homeware, not least in the wake of the Bangladesh clothing factory disaster, since a lot of retailers and their customers are now looking to be more ethical.

In the third flash talk, founder and director of CarbonCulture, Luke Nicholson, explained that the business is aiming at climate change by making it easier for companies to build in sustainability. 'I felt that could be done better by using open data, so we have built a platform to use high-tech metering to monitor carbon use in the workplace', he said. This is then published in real time where employees and partners can see it, creating a stimulus for change. When piloted at the Department for Energy and Climate Change, it achieved 40 per cent take-up among staff and drove a 10 per cent reduction in gas usage. Seven more departments have now adopted it.

Mike Cornwell, CEO of the IDM, gave the final formal presentation to explain the reasons for the two institutes working together and to herald the launch of the joint training programme. 'Direct marketing is founded on the principles of plan, measure, re-iterate, so it has data at its heart', he said.

A key focus for the IDM is employability. 'That term is common currency and means helping young people to become employable. We have been doing that for 15 years', said Cornwell. With the arrival of open data, both students and executives need to gain the necessary skills to support projects, such as those being run by Best Buy, Which? and the Tate. 'That is why we are launching the training scheme in quarter one of 2014'.

A panel session brought the event to a close, with Pinto and Cornwell joined by Max Kelly, former managing director of Virgin Insight, Peter Galdies, director of DQM Group, and the ODI's Kathryn Corrick, head of delivery and digital engagement manager. Kelly noted that data was now front-page news because of the revelations about security service data gathering techniques and that this could have an impact on consumer confidence. 'When I was at Virgin, we said we can't risk any lack of trust in the way we use data. So Virgin Atlantic collects data through its loyalty scheme and customers understand that. But if Virgin Money was to look at their credit card usage and see they had flown on BA, then promoted Virgin Atlantic to them, that crosses a line', he said. This is a matter of policy, even if the terms and conditions of using a product or service might grant a company permission, argued Kelly. 'There is a danger for telcos, financial services providers and ISPs looking to monetise their data that something will go wrong and cause them damage', he said.

Pinto agreed that trust is critical. 'We need a combined effort from industry and the institutes to train people to understand what data is being used for, because the risk is that people don't get it. We need to make people aware of what types of data exist and the different things we can do with it to build trust through positive messages. We can't just rely on regulators', he said. 


\section{Open data certificates}

\section{Anonymizing data is difficult}

\section{'Either data is open or it is not'}

Galdies added to that point by noting that, 'if brands want to be acceptable, they will have to take a lead. Things are already closing up in the form of the European Union's Data Protection Regulation which will impose tighter controls over the ways we collect and use data'. He added that terms and conditions might need to become more explicit and also more transparent about data practices. 'If organisations want to compete, they need data. To get it, they will have to have greater transparency with customers', said Galdies.

For the ODI, Cornish pointed to its set of open-data standards that are intended to help data publishers to ensure that they comply with privacy legislation. These set out four levels at which data may be published, from raw through standard up to expert. However, she added, "nobody gets to that level'.

During the question and answer session, Cornwell noted that industry may not have been clear enough about the value exchange with consumers. 'People love products like social networks, but they don't understand the data that is being collected. How often do we question that'? he asked. Galdies added that consumers are increasingly aware of the value of their personal data and are looking to trade it with organizations.

The issue of what is defined as personal information was also discussed. Kelly said: 'We spent $£ 100,000$ and used a lawyer to answer that question - it was very painful and was not black and white. It depends. Even if you have anonymized it, hashed the identities and used it in aggregate, if somebody has the key for that, it is not anonymous'. Proof of this was when AOL released a set of anonymized subscriber data for researchers and people identified themselves in it.

If an organization is profiling its customers, a small target group might result that, even if anonymized, is recognizable as there are so few candidates within each geographical area, he explained. Ensuring that the units of aggregation are large enough to avoid this risk, while also small enough to be of value, is essential but difficult. 'You may have 10,000 loyalty card holders, but if there is only one in a given postcode, you could identify them even if the data is anonymised', he warned.

That may be one reason as to why more organizations are interested in consuming open data than in publishing it. A lack of skills to manage the process of publication is also an issue, something the new joint training programme is intended to address. Yet the direction of travel is clearly towards openness and releasing data without constraining how it can be used. As Coleman noted, open data has to be open for access to all. 'You can't be open for one business and not for others. It is either open or it is not', he said. 